\title{
A INSERÇÃO DA LÍNGUA INGLESA NO CURRÍCULO DAS SÉRIES INICIAIS DAS ESCOLAS BRASILEIRAS
}

\author{
LA INSERCIÓN DE LA LENGUA INGLESA EN EL CURRICULUM DE \\ LOS AÑOS PRIMARIOS DE LAS ESCUELAS BRASILEÑAS
}

\section{THE INSERTION OF ENGLISH LANGUAGE IN THE CURRICULUM OF THE INITIAL GRADES IN BRAZILIAN SCHOOLS}

\author{
Luiz Fernando SCAGLION ${ }^{1}$ \\ Luciana Aparecida de ARAÚJO ${ }^{2}$ \\ Claudia Regina Mosca GIROTO ${ }^{3}$
}

RESUMO: O aprendizado da língua inglesa não deve ser reservado a uma pequena parcela da sociedade, mas precisa ser um direito assegurado a todos pelo Estado, considerando a ampliação das possibilidades de comunicação e trabalho. Frente à relevância dessa temática, o presente estudo objetivou analisar os estudos que discutem a inserção da língua inglesa no currículo das séries iniciais do Ensino Fundamental, no período de 1996 a 2018, disponíveis na Biblioteca Digital de Teses e Dissertações (BDTD). Foi possível concluir que, desde 1808 até o século XX, o inglês tem sido um idioma elitizado, já que politicamente não era considerado necessário à formação de trabalhadores. Embora mudanças educacionais garantam, atualmente, o ensino dessa língua nas escolas públicas, há evidências da necessidade de maiores investimentos em educação e na formação de professores para a garantia de acesso e ensino de qualidade desse idioma.

PALAVRAS-CHAVE: Língua Inglesa. Currículo. Séries Iniciais.

RESUMEN: El aprendizaje del idioma inglés no debe reservarse a una pequeña parte de la sociedad, sino que debe ser un derecho garantizado para todos por el Estado, considerando la expansión de las posibilidades de comunicación y trabajo. Dada la relevancia de este tema, el presente trabajo ha tenido como objetivo analizar los estudios que discuten la inserción del idioma inglés en el plan de estudios de los grados iniciales de la Escuela Primaria de 1996 a 2018 disponible en la Biblioteca Digital de Tesis y Disertaciones (BDTD). Se concluyó que desde 1808 hasta el siglo XX, el inglés

\footnotetext{
${ }^{1}$ Universidade Estadual Paulista (Unesp), Marília - SP - Brasil. Mestre em Educação pelo Programa de Pós-Graduação em Educação (PPGE), Faculdade de Filosofia e Ciências (FFC). ORCID: https://orcid.org/0000-0002-3757-6383.E-mail: luizscaglion@ gmail.com

${ }^{2}$ Universidade Estadual Paulista (Unesp), Marília - SP - Brasil. Docente do Programa de Pós-Graduação em Educação (PPGE) e do Departamento de Didática, Faculdade de Filosofia e Ciências (FFC). Doutora em Educação. ORCID: https://orcid.org/0000-0003-1147-5039. E-mail: luciana.penitente@ unesp.br ${ }^{3}$ Universidade Estadual Paulista (Unesp), Marília - SP - Brasil. Docente do Programa de Pós-Graduação em Educação (PPGE) e do Departamento de Educação Especial (DEE), Faculdade de Filosofia e Ciências (FFC). Docente do Programa de Pós-Graduação em Educação Escolar (PPGEE), Faculdade de Ciências e Letras (FCLAr). Doutora em Educação. ORCID: https://orcid.org/0000-0001-6267-8085. E-mail: claudia.mosca@unesp.br
} 
ha sido un idioma elitizado, ya que políticamente no se consideró necesario para la capacitación de los trabajadores. Aunque los cambios educativos, actualmente, garantizan la enseñanza de este idioma en las escuelas públicas, existen evidencias de la necesidad de mayores inversiones en educación y capacitación docente para garantizar el acceso y la enseñanza de calidad de ese idioma.

PALABRAS CLAVE: Lengua inglesa. Curriculum. Años primarios.

ABSTRACT: English language learning should not be reserved only for a small part of society, but it must be a guaranteed right to all and provided by the State, considering the expansion of communication and work possibilities. Given the relevance of this theme, the present study aimed to analyze the studies that discussed the insertion of the English language in the curriculum of the initial grades of Elementary School from 1996 to 2018 available in the Digital Library of Theses and Dissertations (BDTD). It reached the conclusion that from 1808 until the twentieth century, English has been a language for the elite and politically the language was not considered necessary for the training of workers. Although educational changes currently guarantee the teaching of this language in public schools, there is evidence of the necessity for greater investments in education and teacher training to ensure access and quality teaching of this language.

KEYWORDS: English language. Curriculum. Initial grades.

\section{Introdução}

Por um longo período o ensino público ficou voltado às elites brasileiras. Nas primeiras décadas do século XX ocorreram movimentos voltados para a alfabetização e, posteriormente, um longo período em que a educação se voltou para a profissionalização dos trabalhadores. Nesse contexto, a Língua Inglesa (LI) permaneceu por quase dois séculos como privilégio de uma parcela pequena da população brasileira.

As mudanças na educação brasileira vieram a partir das novas políticas educacionais e do período pós-promulgação da Constituição de 1988 (BRASIL, 1988) e com o estabelecimento da Lei de Diretrizes e Bases da Educação Nacional (LDBEN) (BRASIL, 1996). Conforme elucidado por Ferreira (2014, p. 147). “[...] as mudanças vivenciadas nas últimas duas décadas na educação brasileira estão envoltas na evolução das LDBs e, especialmente, no uso de Políticas Públicas Educacionais voltadas para a construção de uma educação inclusiva, cidadã e de qualidade."

Brzezinski (2008) afirma que, embora tenham ocorrido anos de discussões em torno da educação brasileira, ainda há grandes avanços, capazes de levar a uma educação pública de qualidade. Entretanto, o reordenamento dos sistemas educativos 
que está inscrito na LDBEN (BRASIL, 1996) poderá criar contextos de relações estruturais de transformação, de reforma e de inovação educacional, diminuindo a distância entre a lei formulada e o real.

O reconhecimento da necessidade de se aprender uma língua estrangeira, foi estabelecida na LDBEN (BRASIL, 1996) desde seu texto original e consta em seu Artigo 36 que "Será incluída uma língua estrangeira moderna, como disciplina obrigatória, escolhida pela comunidade escolar, e uma segunda, em caráter optativo, dentro das disponibilidades da instituição”. Consideramos que o interesse e necessidade pelo aprendizado de um idioma tem se ampliado cada vez mais pela população brasileira, perspectivados pela possibilidade de alcance de melhores condições de trabalho dentro e fora do país e de garantia da boa comunicação e troca de conhecimentos. Costa (1987, p. 2) acrescenta que “[...] o crescente interesse pelas línguas modernas, enquanto disciplinas escolares, se tornou claro exatamente no momento em que a educação deixou de ser um monopólio dos ricos e veio a ser considerada essencial para ascensão social”.

Acreditamos que não se pode pensar na língua inglesa como um idioma que deva ser elitizado para acesso e aprendizado de uma pequena parcela da população, mas compreendido como direito assegurado pelo Estado a todos. Com base nessa premissa, buscamos responder às seguintes questões: o que dizem as teses e dissertações sobre a inserção do ensino do inglês no currículo dos anos iniciais do Ensino Fundamental das escolas brasileiras? Quais são as garantias legais para a continuidade do ensino de inglês em escolas públicas?

Com vistas a contribuirmos com a ampliação das discussões sobre essa temática, tendo em vista, então, a importância da língua inglesa no currículo e a garantia desse ensino com qualidade nas escolas públicas brasileiras, este estudo objetivou analisar os estudos que discutem a inserção da língua inglesa no currículo das séries iniciais do Ensino Fundamental, no período de 1996 a 2018, disponíveis na Biblioteca Digital de Teses e Dissertações (BDTD).

\section{Metodologia}

Para demostrar a relevância da temática, foi realizada revisão bibliográfica na Biblioteca Digital de Teses e Dissertações (BDTD) por abranger significativamente o conjunto de teses e dissertações brasileiras. Para tal, procedemos pela busca das teses e 
dissertações publicadas a partir do ano de 1996, ano da promulgação da LDBEN (BRASIL, 1996) até o ano de 2018, ocasião em que ocorreu o levantamento dos dados aqui considerados. A partir dessa busca as teses e dissertações, foram analisadas a partir de três eixos: "História das políticas públicas de Língua Estrangeira", "Políticas públicas e língua inglesa”, e "A língua inglesa no currículo escolar”. O delineamento do corpus investigativo foi realizado com o uso das expressões: "História das políticas públicas de Língua Estrangeira", "Políticas públicas e língua inglesa”, "A língua inglesa e o currículo escolar".

A busca realizada com o uso da expressão "História das políticas públicas de Língua Estrangeira" resultou em 139 trabalhos, sendo selecionadas apenas seis pesquisas por trabalharem com o ensino da língua inglesa e suas respectivas políticas públicas. Destaca-se que entre estas, a maioria optou por um período histórico mais específico, século XIX, a Era Vargas, ou o século XXI. Primeiramente foi feita a seleção por meio dos títulos dos trabalhos que convergiam para o que se almejava investigar, posteriormente a leitura destes resumos e sumários, para confirmarmos a pertinência à pesquisa. A expressão "Políticas públicas e língua inglesa", trouxe 239 trabalhos, mas apenas 13 novos trabalhos foram relevantes, já que abordavam o ensino do inglês no currículo, suas políticas públicas, com ênfase em análises sobre a perspectiva histórica do ensino de língua inglesa no Brasil. Por sua vez, a utilização da expressão "A língua inglesa e o currículo escolar" resultou em 252 trabalhos, tendo sido considerados apenas dez como mais relevantes para esse estudo.

A análise desses dados ocorreu a partir da leitura, na íntegra, desse conjunto de teses e dissertações considerado pertinente ao objetivo do presente estudo. Para fins de apresentação e discussão, os dados foram organizados em três eixos, cuja denominação se deu a partir das expressões de busca utilizadas: 1) "História das políticas públicas de Língua Estrangeira"; 2) "Políticas públicas e língua inglesa"; e 3) "A língua inglesa no currículo escolar", considerando as pesquisas que trabalharam com as alterações da legislação da LI no currículo das escolas e também os trabalhos que analisaram os documentos que envolvem o estudo da LI, que demonstraram pertinência implícita ou explícita com a temática abordada nesse estudo. 


\section{Resultados e discussões}

O eixo 1 - "História das políticas públicas de Língua Estrangeira” contemplou duas teses de doutorado e quatro dissertações, totalizando seis produções que guardavam relação com as questões de pesquisa e/ou objetivo desse estudo.

Souza (2005), em sua tese de doutorado defendida na Unicamp, “O Movimento dos sentidos sobre línguas estrangeiras no Brasil: discurso, história e educação" buscou compreender o percurso dos sentidos das línguas estrangeiras no Brasil, a partir da perspectiva teórica da Análise de Discurso. Realizou uma análise da história das línguas estrangeiras no país desde, 1500 até o governo Fernando Henrique Cardoso em 2002, utilizando a legislação educacional brasileira para tal análise. Concluiu ser necessária a propagação dos centros de línguas públicos para a melhoria do ensino de idiomas no Brasil, como um processo de identificação subjetiva.

A tese de Costa (2007): "Pode ser em inglês? Não. Em português primeiro. Ensino de língua inglesa para crianças em contextos emergentes no país: um estudo de caso" abordou a análise do ensino de língua estrangeira para crianças no ensino fundamental e a formação continuada de professoras de idiomas. Foi realizado estudo de caso e o uso de entrevistas com professoras.

Carvalho (2010), na dissertação “A Língua Inglesa no Ensino Básico: processo de identificação no contexto de uma escola pública" teve como objetivo verificar os diferentes efeitos de sentido produzidos por discursos e investigar sua interferência no processo de identificação. Foi adotada uma abordagem transdisciplinar, subsidiada por pressupostos da Análise de Discurso, da Psicanálise, da Filosofia e dos Estudos Culturais. Além disso, foi feita uma análise histórica do ensino de língua estrangeira no Brasil, porém predominou a análise de métodos de ensino de idiomas e a discussão sobre o ensino de idiomas no século XIX. Discutiu também as representações do ensino de idiomas no país e entrevistas com professores de inglês. Concluiu que o sujeito aprendiz de inglês, no contexto de uma escola pública, identifica-se com a representação do lugar ocupado pelo falante de inglês.

Costa (2014), na dissertação defendida na UFAM e intitulada "Políticas Linguísticas: o ensino de línguas estrangeiras em escolas públicas do estado do Amazonas" objetivou compreender como se configuram as políticas linguísticas propostas para a rede estadual no estado do Amazonas e como, na prática, se concretizam em escolas públicas de Manaus/AM. Realizou uma análise histórica do 
ensino de língua estrangeira no Brasil, além de uma análise dos efeitos da globalização na nova configuração da sociedade, defendendo a democratização do saber e a formação dos cidadãos, subsidiada pela Análise do Discurso. Também foi apresentada a influência do estudo da LI e das leis federais, principalmente os PCN e suas implicações nas políticas estaduais no Amazonas. Concluiu que há grande importância da participação do professor e da comunidade como atores do processo educacional na elaboração das políticas educacionais.

Rocha (2016), em sua dissertação "O ensino de língua estrangeira em Niterói: Um Olhar Político-Linguístico", teve como objetivo traçar um panorama geral das ações realizadas pelo município de Niterói e pelo estado do Rio de Janeiro nas políticas para o ensino de línguas estrangeiras. Fez uma análise histórica sobre o ensino de línguas estrangeiras, principalmente no estado do Rio de Janeiro e, entre suas conclusões, destacou o privilégio das elites durante os dois últimos séculos no Brasil em relação ao aprendizado da língua inglesa. A autora trabalhou principalmente com a LDBEN (BRASIL, 1996), mas predominou na dissertação a análise das escolas e o ensino bilíngue em Niterói/RJ. Ademais, apresentou como principais problemáticas de ensino a formação docente ineficiente e a violência nas escolas e como proposição a necessidade de uma política linguística com planejamento mais eficaz.

A tese de Santos (2017), intitulada "Entre a tradição e a inovação: professores e compêndios de inglês do século XIX”, apresentou uma análise bem contundente do ensino de língua inglesa no Brasil do século XIX. Teve como objetivo identificar, no cenário educacional do Brasil oitocentista, as lutas por um espaço para o ensino do inglês. Para tanto, a autora examinou a legislação para o ensino de línguas ou relacionada aos assuntos referentes ao inglês, visando acompanhar o percurso traçado pela língua inglesa em busca de conquista de espaço. Enfatizou também a importância do Colégio Pedro II para a educação no século XIX. As fontes utilizadas foram a legislação do século XIX, alguns compêndios oitocentistas e jornais do período, justificando a combinação dessas três fontes por terem sido importantes para comparar e contrastar as informações, já que envolveram professores ou o ensino de inglês no país e a sua importância na sociedade. Concluiu que o ensino de idiomas era predominantemente voltado à gramatica e tradução e que foram poucas as inovações verificadas nos materiais publicados, mesmo estando envolvidas em um discurso por práticas mais indutivas, recorrentes desde o século XVI. 
No eixo 2 "Políticas públicas e língua inglesa" foram consideradas cinco teses de doutorado e oito dissertações, totalizando 13 produções.

A tese de Oliveira (2006), “A instituição do ensino das Línguas Vivas no Brasil: o caso da Língua Inglesa (1809-1890)", abordou a institucionalização do ensino de línguas vivas no Brasil e sua configuração como disciplina escolar, especificamente a LI. A principal fonte documental utilizada foi a legislação educacional nacional, mas o autor utilizou também Planos de Estudo e Programas de Ensino, assim como atas de sessões parlamentares e reuniões da Congregação do Colégio Pedro II. Destacou a importância do Colégio de Pedro II; dividindo o ensino, nesse período, em três fases, a primeira (1809-1837), quando o ensino de língua estrangeira era predominantemente instrumental; a segunda (1837-1870) quando havia aprendizagem para finalidade literária, qualificando os alunos para os exames preparatórios e a terceira fase (18701890), que tinha finalidade prática, quando as línguas estrangeiras eram utilizadas como meio de comunicação para o desenvolvimento das habilidades orais dos alunos. Destacou o conhecimento elitista das línguas estrangeiras e, no caso da língua inglesa, a sua importância para as negociações comerciais no século XIX.

Vidotti (2012), com a tese "Politicas linguísticas para o ensino de língua estrangeira no Brasil do século XIX, com ênfase na língua inglesa”, teve como objeto de estudo o discurso político-educacional sobre o ensino de língua estrangeira no Brasil. O corpus abrangeu principalmente a análise das leis, decretos, debates parlamentares e políticas públicas que se voltaram para o ensino da língua inglesa e também francesa. $\mathrm{O}$ recorte histórico partiu do estudo dos idiomas estrangeiros a partir do século XVIII em solo brasileiro. Concluiu que as línguas estrangerias eram saberes úteis ao Estado, pois os idiomas eram necessários à instrução pública; além disso, destacou a influência europeia na cultura e política brasileira.

Maciel (2013) defendeu a tese "Negociando e reconstruindo conhecimentos e práticas locais: a formação de professores de língua inglesa e os documentos oficiais”, destacando a relação entre os documentos oficiais e a formação de professores de LI para o Ensino Médio, discutindo, com os professores de inglês, as orientações curriculares no estado do Mato Grosso do Sul definidas pelo MEC, além de ter como um dos enfoques principais a sociedade globalizada e o papel relevante da LI. A pesquisa foi de caráter qualitativo com características colaborativa e etnográfica, bem como subsidiada pela legislação educacional nacional. 
Jucá (2017), em sua tese "Das histórias que nos habitam: por uma formação de professores de inglês para o Brasil", discutiu a formação dos professores de inglês no Brasil e a falta de interesse na profissão. O estudo baseou-se em teorias pós-modernas, utilizando conceitos pós-estruturalistas e coloniais relacionados às concepções de língua, discurso, epistemologia e identidade, para melhor compreensão das influencias modernas sobre a construção histórica da docência e da identidade docente. Reafirmou a necessidade de uma formação docente pautada no letramento jurídico para a promoção de mudanças na elitização do aprendizado dessa língua.

Correa (2018), na tese “A política de formação de professores de língua inglesa e os desafios da prática cotidiana na escola pública", discutiu a análise do ensino e formação de professores de Língua Inglesa graduados na Universidade Federal do Amazonas, no período de 2004 a 2010. Verificou os principais aspectos da política educacional voltada para o ensino da Língua Inglesa no Brasil, tendo trabalhado, com os documentos oficiais, a LDBEN (BRASIL, 1996) e os PCNs (BRASIL, 1997). O eixo condutor da pesquisa foi o ensino e a aprendizagem de Línguas Estrangeiras na Rede Púbica da cidade de Manaus/AM. A pesquisa, de natureza qualitativa, foi ancorada na análise textual descritiva.

Oliveira (2003), na dissertação "Políticas de Ensino de Línguas Estrangeiras em Escolas Públicas do Estado de São Paulo”, teve como objetivo elaborar um estudo que dissertasse sobre os fatores configurantes das políticas de ensino de línguas estrangeiras em uma escola pública do estado de São Paulo e que determinasse o processo de constituição do discurso do professor de inglês. O estudo apresentou um breve histórico sobre o ensino das línguas estrangeiras no Brasil e a política de ensino. Entretanto, o foco da dissertação foi o sujeito e as formações imaginárias no aprendizado de uma língua estrangeira.

Na dissertação de Sousa (2006), em "Professores de Inglês da Escola Pública: investigações sobre suas identidades numa rede de conflitos", o objetivo foi analisar a construção das identidades de professores de inglês do ensino público, porém, há analises sobre a educação sob o modelo neoliberal e a importância de inglês no mundo globalizado. Foi feita uma pesquisa qualitativa, de cunho etnográfico, através de entrevistas e questionários respondidos por professores de escolas públicas da cidade de São Paulo.

Oliveira (2006), com a dissertação "O imaginário do aluno sobre a língua inglesa na constituição de sua subjetividade", abordou o ensino de inglês na escola pública, a 
falta de motivação para o aprendizado da LI e a insuficiência do ensino na escola para que o aluno aprenda uma língua estrangeira. Para essa autora, o aluno enaltece uma língua, a inglesa, mas é uma contradição, pois não tem praticamente nenhum contato com a mesma. Realizou uma análise interpretativa e descritiva do corpus investigativo, por meio de entrevistas semiestruturadas com professores e alunos de inglês das escolas públicas. Concluiu ressaltando a importância do professor de língua estrangeira como grande mediador entre o aluno e a nova língua.

A dissertação de Emilio (2008), intitulada "Ensino de língua inglesa no ensino fundamental: aproximação às representações sociais de professores sobre o componente curricular", utilizou como referencial teórico de análise a Teoria das Representações Sociais e os estudos sobre Trabalho Docente, adotando como procedimento metodológico a teoria do Núcleo Central das Representações Sociais e a análise de conteúdo. As análises abordaram a história da língua inglesa e sua importância no currículo, as aulas voltadas para o ensino do inglês instrumental e a importância e contradições da LDBEN (BRASIL, 1996) e dos PCN (BRASIL, 1997) durante a República. Concluiu relatando que os significados que os professores atribuem à sua prática derivam de sua formação profissional, da prática docente, de suas experiências de vida e através de suas relações entre si. Propôs escrever uma nova história que apague o pensamento de que não se aprende inglês na escola de ensino regular. Destacou, para isto, a necessidade de ações voltadas para a articulação entre as políticas públicas, o contexto organizacional escolar e a formação de professores.

Nascimento (2010), em sua dissertação “A formação do professor de língua inglesa e a legislação: o caso do curso de letras - habilitação português-inglês da UFS" abordou, como foco principal, a formação inicial de professores em Letras. Realizou pesquisa qualitativa, do tipo crítico-descritiva. Utilizou o método dialético e o aprofundamento teórico através de pesquisa bibliográfica e documental. Apresentou análise sobre o neoliberalismo e a sociedade atual. Destacou as políticas públicas e os documentos oficiais, principalmente a LDBEN (BRASIL, 1996), o ensino de inglês e sua relação com o curso de Letras e a importância dos PCN (BRASIL, 1997) na educação brasileira em um mundo globalizado. Uma de suas conclusões é a de que a universidade, especialmente o curso de formação de professores em língua inglesa, tem atuado através da lógica da simples prestação de serviço e não como produtora de conhecimento; além do problema de oferecer uma carga horária reduzida e insuficiente para o ensino do inglês. 
$\mathrm{Na}$ dissertação de Vicentin (2013), "Inglês nos anos iniciais do Ensino Fundamental público: de representações de professores a políticas linguísticas", a inquietação da autora residiu no aprendizado da LI no Ensino Fundamental I, ao trabalhar com as diretrizes curriculares e com os professores de escolas públicas de Campinas, frente às políticas linguísticas e sua eficiência em sala de aula. A pesquisa qualitativa interpretativista se insere na área da Linguística Aplicada. Enfatizou a importância do Inglês no mundo contemporâneo e sua constante expansão. Partiu do princípio que os professores têm seu papel de policy makers. Os resultados indicaram, entre outras questões, que, embora os professores de língua inglesa entrevistados tenham atuado como policy makers de um modelo de política linguística ascendente, eles não se reconhecem, ou parecem ainda não ter consciência do seu papel no estabelecimento dessas políticas. Concluiu que, para que seja possível a implementação efetiva do ensino da língua inglesa na matriz curricular oficial dos anos iniciais do Ensino Fundamental, é necessário haver um modelo de política linguística específico para o ensino de Língua Estrangeira para Crianças.

Em sua dissertação, "O ensino de língua inglesa em escolas públicas: Um diálogo possível", Andrade (2015) partiu da indagação sobre a falta de efetividade do ensino da língua inglesa nas escolas públicas brasileiras. O autor partiu do princípio de que a LDBEN (BRASIL, 1996) garante a obrigatoriedade do ensino de inglês a partir da $5^{\mathrm{a}}$ série do Ensino Médio, respaldando por lei o ensino de língua estrangeira, logo, este deveria receber mais incentivos, políticas públicas, mecanismos e estruturas que o tornasse mais efetivo para que apresentasse os resultados esperados em sala de aula. Realizou análise de como as políticas públicas têm funcionado na prática, além de trabalhar com o professor de inglês como sujeito, pois o autor acredita que o ponto de partida para o efetivo aprendizado de língua inglesa em nosso país é o professor; além de destacar problemas de formação para o ensino do idioma.

Miranda (2015), em sua dissertação "Ensino de língua inglesa no Brasil, políticas educacionais e a formação do sujeito da educação básica", procurou relacionar as políticas públicas nacionais com as internacionais, através de um estudo bibliográfico e documental, para tanto, analisou os enunciados dos textos oficiais, mostrou a relação direta das políticas internacionais com os aspectos internos do funcionamento das escolas no país. O trabalho abordou a relação entre o contexto histórico da língua inglesa e as políticas durante os séculos XIX e XX; trabalhou com os principais documentos oficiais, com destaque para a LDBEN (BRASIL, 1996) e os PCN 
(BRASIL, 1997). Relacionou o conhecimento do idioma ao mundo do trabalho, globalização e à importância da educação. Conclui que a língua inglesa, especialmente, teve, em sua trajetória, estreita relação com as mudanças das relações de produção e ressaltou a importância de se compreender a função social de uma língua estrangeira na escola pública.

O eixo 3 "A língua inglesa e o currículo escolar" compreendeu uma tese de doutorado e nove dissertações, totalizando 10 produções que evidenciaram relação implícita ou explícita com as questões de pesquisa e/ou objetivo desse estudo.

Pucci (2017), em sua tese "O ensino da língua inglesa na escola pública: um olhar para os sentidos construídos por seus professores acerca de onde, para quem, por que e como ensinam" realizou entrevistas com sete professoras de escolas públicas, partindo da tese de que os discursos que (des) valorizam a língua inglesa e a docência na escola pública participam na construção dos sentidos que as professoras elaboram sobre o processo de ensino e aprendizagem. A autora fez uma análise histórica da língua inglesa e das políticas públicas envolvidas, considerando o período de 1808 até a atualidade. Realizou análise da LDBEN (BRASIL, 1996) e dos PCN (BRASIL, 1997). Concluiu que, atualmente, há dificuldade em reconhecer e tornar reconhecida a língua inglesa como um conhecimento escolar formativo e em mostrar sua relevância aos alunos, um dos fatores está no fato de a escola pública ser um ambiente caracterizado como especificamente inapropriado para o ensino e aprendizagem da língua inglesa.

Lima (2005) buscou, na dissertação “Os PCN-LE e a prática docente: realidade ou utopia”, relacionar a prática docente com os PCN (BRASIL, 1997). Realizou entrevistas com professores de inglês de escolas privadas de Brasília, em busca de saber se as diretrizes dos PCN (BRASIL, 1997) estariam sendo utilizadas na prática. Promoveu uma investigação qualitativa através do método da pesquisa documental. Concluiu que não houve leitura, ou havia pouco conhecimento dos PCN (BRASIL, 1997), logo, na prática, esses documentos oficiais não alteraram em nada o ensino em sala de aula.

Menegazzo (2006), na dissertação: “Os PCNEM e $\mathrm{PCN}_{+}$de língua estrangeira: sugestões aplicáveis", direcionou a pesquisa sobre como é trabalhada a leitura de textos em inglês em salas de aula, numa escola pública e numa escola particular, utilizando as pesquisas quantitativa e etnográfica. A autora trabalhou com entrevistas através de questionários com professores de inglês e com a observação de aulas. Como referencial teórico utilizou os conceitos e estratégias de leitura. Concluiu que somente alguns itens 
dos Parâmetros são utilizados na prática, pois, na sua elaboração, foi desconsiderada a situação real da escola no Brasil e que os maiores problemas enfrentados em sala são o grande número de alunos e a indisciplina.

A dissertação de Rocha (2006), cujo título é "Provisões para ensinar LE no ensino fundamental de $1^{\mathrm{a}}$ a $4^{\mathrm{a}}$ séries: dos Parâmetros oficiais e objetivos dos agentes, de natureza qualitativa e base etnográfica", teve como foco o processo de ensinar e aprender uma língua estrangeira nos dois primeiros ciclos do Ensino Fundamental subsidiada pela análise dos PCN-LE. Foi feita uma análise documental, assim como trabalhou com os agentes do processo ensino-aprendizagem de forma direta e indireta e ouviu diretores, coordenadores, professores, alunos e pais. Concluiu que há a necessidade de investigação mais profunda a respeito das crenças e objetivos de alunos e professores para redimensionar o ensino de idiomas nas escolas regulares.

Covino (2006) analisou a prática docente expressa nos PCN (BRASIL, 1997) na dissertação "Os parâmetros curriculares nacionais e o ensino de língua inglesa: sintonia entre teoria e prática", Destacou que na teoria o fazer docente tornou-se mais complexo, mas na prática o professor assume o papel de transmissor de conhecimento. O objetivo foi o de verificar até que ponto a prática docente dos professores de LI, nas escolas de Ensino Fundamental da Grande São Paulo, se aproxima do preconizado por esse documento. Fez uma breve retrospectiva da educação no Brasil, das alterações da legislação referente à língua inglesa, no recorte histórico de 1808 até a LDBEN de 1996. Uma das conclusões ressaltou que esse documento apresenta a exigência de um profundo conhecimento teórico do processo de ensino e aprendizagem, o que é considerado pela autora como inadequado para a realidade da educação brasileira, pois se espera do professor múltiplas competências e habilidades, defendendo então a melhoria da formação dos professores de inglês.

Na dissertação de Santos (2014) intitulada "O ensino de língua inglesa em duas escolas pública de Cuiabá: com a palavra, as professoras”, foram abordadas as concepções de professoras de língua inglesa de escolas públicas sobre a atual situação do ensino, a metodologia e também os documentos oficiais. Realizou coleta de dados através de um questionário semiaberto aplicado a quatro professoras do Ensino Fundamental em duas escolas de Cuiabá. A autora trabalhou com a análise da LDBEN (BRASIL, 1996) e dos PCN (BRASIL, 1997). Concluiu que os alunos são colocados como receptores de conteúdo, além de não ser priorizada a formação cidadã, pois não se 
possibilita a continuação de seus estudos ou a progressão no trabalho, fatores que divergem da concepção desses documentos oficiais.

Santos (2015) procurou estudar, na dissertação "Proposta curricular do Estado de São Paulo: a relação entre as crenças e a prática de dois professores de inglês", a aplicação da Proposta Curricular do Estado de São Paulo, o que mudou em sala de aula a partir dos pressupostos teóricos presentes no currículo, as diferenças entre as crenças e as práticas em sala de aula. A investigação foi de natureza qualitativa, de cunho etnográfico, caracterizando-se como um estudo de caso, pois a autora trabalhou com as crenças e ações de duas professoras de LI em escola pública, realizou observação de aulas, com notas de campo e gravações em áudio e também trabalhou com um questionário e com uma entrevista com cada professora. As políticas educacionais foram utilizadas como instrumento de mediação entre ensino e aprendizagem, numa perspectiva sócio cultural. Concluiu que, para que ocorra uma verdadeira reforma curricular no Estado, não basta que se criem documentos e prescrições na tentativa de implementar uma reforma de cima para baixo, pois uma reforma educacional deve ter o professor como figura central. Ressaltou ser necessário que os docentes tenham a oportunidade de refletir sobre suas crenças, a fim de que internalizem os pressupostos teóricos que embasam a Proposta Curricular.

Em sua dissertação "Políticas linguísticas e as representações da prática docente no ensino fundamental: Língua inglesa em foco”, Seccato (2016) relatou que são poucas as pesquisas que deram ênfase à LI e às políticas públicas no Brasil, além de ressaltar a maior importância do idioma no mundo globalizado, dedicando-se a uma análise geral das políticas mais recentes no país, principalmente os PCN (BRASIL, 1997). Realizou estudo de caso de um projeto de Londrina - PR para o ensino de inglês logo no início da escolarização, ou seja, no ensino fundamental I e trabalhou com estudos de linguística e entrevistas com professores. Concluiu que o acesso à LI ainda continua excluindo grande parte das crianças na escola e que uma grande falha é ter acesso a uma legislação nacional que não oferece essa oportunidade a todos, pois define o inglês como opcional, a ser oferecido da maneira que as instituições educacionais quiserem ou puderem materializar esse conteúdo no currículo.

Tomasel (2017), na dissertação "To be or not to be": A produção da docência de Língua Inglesa em documentos legais”, enfatizou o pós-estruturalismo e a análise de documentos referentes à língua estrangeira, sendo estes os PCN (BRASIL, 1997) e a Base Nacional Comum Curricular (BNCC) (2017), através do conceito de discurso 
como ferramenta teórico-metodológica, buscando mostrar como esses documentos descrevem, orientam e instituem a forma de ser e de fazer dos docentes de LI. Concluiu que os documentos legais fornecem um panorama que coloca a LI nas escolas públicas em lugar desprivilegiado no currículo, o que reforça a diferença entre o ensino na escola regular do ensino em uma escola de idiomas. Ressaltou, ainda, o processo de redução de conteúdo na relação ensino/aprendizagem.

Fonseca (2018), em sua pesquisa de doutorado intitulada “A imposição do inglês como política linguística: na contramão do plurilinguismo", teve como objetivo investigar os primeiros efeitos provocados pela Lei 13.415 (BRASIL, 2017), que trata da oferta obrigatória do inglês no currículo do Ensino Fundamental, a partir do sexto ano, e da sua obrigatoriedade nos currículos do Ensino Médio. A autora também trabalhou com a análise dos documentos LDBEN (BRASIL, 1996), PCN (BRASIL, 1997) e BNCC (BRASIL, 2017) e fez uma avaliação da importância do inglês na modernidade e de sua obrigatoriedade nos currículos. A tese teve base na historiografia e em trabalhos no campo da História do Ensino das Línguas. No caso da LDBEN (BRASIL, 1996), a autora trabalhou com as alterações desde 1961 e suas fontes foram a legislação e historiografia educacionais. Defendeu que não haja a exclusividade do inglês no currículo, como a legislação educacional tem caminhado, mas que seja oferecido um currículo plurilíngue. Concluiu que é preciso subsidiar ações que levem à criação de políticas linguísticas articuladas entre si, para que o ensino massivo do inglês dê lugar à construção de currículos plurilíngues.

De maneira geral, a maioria das teses e dissertações abordou, no que se refere aos documentos oficiais, a LDBEN (BRASIL, 1996) e os PCN (BRASIL, 1997), principalmente por serem os principais documentos que tangem o ensino e a língua inglesa no currículo, pois fornecem respaldo para a permanência do estudo do inglês, além de fornecer as diretrizes para professores trabalharem em sala de aula e para que o ensino possa ter melhorias. Entretanto, as pesquisas também demonstraram os principais problemas enfrentados por professores de inglês, tais como: a indisciplina em sala; o desinteresse dos alunos; a falta de conhecimento dos documentos oficiais ou mesmo como aplicá-los em sala; além de problemas de formação dos professores; dificuldades que necessitam ser alteradas em conjunto para poder mudar o quadro do ensino de língua inglesa em sala.

A preocupação ou solução encontrada, nos trabalhos aqui pesquisados, para a melhoria do ensino e aprendizado de inglês nas escolas públicas residiu, 
predominantemente, na formação de professores e na formação continuada. É importante ressaltar que poucos estudos abordaram a história da língua inglesa em nossa sociedade e no currículo escolar, pois em mais de 200 anos de legislação e de ensino da língua inglesa no Brasil, poucos pesquisadores dedicaram-se a este assunto.

Os estudos, de modo geral, denunciaram a elitização do Inglês como idioma, desde as primeiras políticas públicas destinadas ao ensino desse idioma no país, com a vinda de D. João VI ao Brasil, em 1808, até praticamente em todo o século XX. Foi possível constatar a influência das políticas públicas educacionais que, na prática garantiram que apenas a elite detivesse o conhecimento do Inglês, seja durante o século XIX, com o predomínio da escravidão e de uma classe média insípida, seja no século $\mathrm{XX}$, com políticas destinadas à formação de trabalhadores para as indústrias no Brasil pois, na visão dos governantes, não havia necessidade alguma de garantir aprendizado de um idioma estrangeiro a grande parte da população; quem desejasse tal conhecimento, deveria pagar pelo ensino em instituições particulares.

Por meio da história da língua inglesa em nosso país, desde o marco inicial, 1808, como anteriormente estabelecido, pode ser constatada a busca por sua hegemonia, principalmente nas últimas décadas, pois, em pouco mais de 200 anos, da complexa gama de idiomas estrangeiros que era oferecida aos alunos que frequentavam as escolas, foi reduzida, em nossos documentos oficiais, à predominância da língua inglesa e a sua obrigatoriedade no currículo escolar. Durante o século XX, é importante ressaltar a preocupação que foi dada a educação como formação de trabalhadores, ou seja, a educação voltada para o ensino profissionalizante, para poder oferecer às empresas mão de obra, situação que fora agravada durante a Ditadura Militar (1964-1985). Logo, de maneira geral, no século XX também não foi garantido o acesso à cultura e nem a possibilidade de ascensão social a grande maioria da população brasileira. O inglês, como segunda língua, vai ascendendo ao posto de principal idioma estrangeiro, mas permanece privilégio de poucos, a educação pública não possibilita, na grande maioria das escolas, que o aluno aprenda a falar inglês. Cabe destaque, ainda, ao reduzido número de estudos com pertinência explícita ao ensino da LI nas séries iniciais do Ensino Fundamental, o que demonstra a necessidade de pesquisas e publicações que abordem, especificamente, essa temática. 


\section{Considerações finais}

Após as análises e discussões apresentadas, compreendemos que temos que formar cidadãos que possam se encaixar na sociedade do século XXI, pois o mundo globalizado demanda a língua inglesa como segundo idioma, entretanto, o que se nota nas políticas públicas brasileiras desde 1808 e que, permanece atualmente, é a falta de preocupação com a qualidade, falta de formação de professores para se tornarem qualificados para dar aula, pois muitas escolas normais nem incluíam no currículo o inglês, impossibilitando o professor de ensinar algo que nunca aprendeu. Tivemos dois séculos de descaso com a população como um todo, houve preconceito e elitismo, pois, indiretamente, as políticas públicas até 1988, teriam o preceito de não ver necessidade alguma de um cidadão pobre ou um pobre cidadão aprender uma língua estrangeira.

O descaso ao ensino público durante mais de dois séculos, assim como a falta de real aplicação de políticas públicas nas salas de aulas, também se refrata no ensino de má qualidade da língua inglesa e, infelizmente, não apenas dessa disciplina. Com a alta competitividade do mercado de trabalho, o inglês muitas vezes não é nem mesmo diferencial, mas obrigatório para os mais diversos cargos, mesmo os que oferecem salários medianos.

\section{REFERÊNCIAS}

ANDRADE, Ezequias Felix de. O ensino de língua inglesa em escolas públicas: um diálogo possível. 2015. 70f. Dissertação (Mestrado em Linguística) - Universidade Federal da Paraíba, João Pessoa, 2015.

BRASIL. Constituição da República Federativa do Brasil. Congresso Nacional. Brasília, DF, 1988. Disponível em: http://www.planalto.gov.br/ccivil_03/Constituicao/Constituicao.htm. Acesso em: 25 jul. 2018.

BRASIL. Parâmetros Curriculares Nacionais: Terceiro e Quarto Ciclos do Ensino Fundamental: Língua Estrangeira. Disponível em: http://portal.mec.gov.br/seb/arquivos/pdf/pcn_estrangeira.pdf. Acesso em: 19 jun. 2019.

BRASIL. Parâmetros Curriculares Nacionais. Disponível em: http://portal.mec.gov.br/seb/arquivos/pdf/livro01.pdf. Acesso em: 19 jun. 2019.

BRASIL. Base Nacional Comum Curricular. Disponível em:

http://portal.mec.gov.br/conselho-nacional-de-educacao/base-nacional-comumcurricular-bncc. Acesso em: 19 jun. 2019. 
BRZEZINSKI, Iria (Org.). LDB dez anos depois: reinterpretação sob diversos olhares. São Paulo: Cortez, 2008.

CARVALHO, Valceli Ferreira de. A Língua Inglesa no Ensino Básico: processo de identificação no contexto de uma escola pública. Dissertação (Mestrado em Estudos Linguísticos e Literários), Faculdade de Filosofia Letras e Ciências Humanas, Universidade de São Paulo- SP, 2010.

CORREA, Edith Santos. A política de formação de professores de língua inglesa e os desafios da prática cotidiana na escola pública. Tese (Doutorado em Sociedade e Cultura) - Universidade Federal do Amazonas, Manaus, AM, 2018.

COSTA, Rinaldo Vitor da. Pode ser em inglês? Não. Em português primeiro. Ensino de língua inglesa para crianças em contextos emergentes no país: um estudo de caso. Tese (Doutorado em Linguística Aplicada): Universidade Estadual de Campinas, Campinas, SP, 2007.

COSTA, Mirley Tereza Correia da. Políticas Linguísticas: o ensino de línguas estrangeiras em escolas públicas do estado do Amazonas. Dissertação (Mestrado em Letras) - Universidade Federal do Amazonas, Manaus, AM, 2014.

COVINO, Liliana. Os parâmetros curriculares nacionais e o ensino de língua inglesa: sintonia entre teoria e prática. 2006. Dissertação (Mestrado em Letras), Universidade Presbiteriana Mackenzie, São Paulo, 2006.

EMILIO, Rejane Maria. Ensino de língua inglesa no ensino fundamental: aproximação às representações sociais de professores sobre o componente curricular. Dissertação (Mestrado em Educação), Universidade Católica de Santos, Santos, SP, 2008.

FERREIRA, Cleia Simone; SANTOS, Everton Neves. Políticas Públicas Educacionais: apontamentos sobre o direito social da qualidade na educação. Revista LABOR, n. 11, v. $1,2014$.

FONSECA, Ana Lúcia Simões Borges. A imposição do inglês como política linguística: na contramão do plurilinguismo. Tese (Doutorado em Educação) Universidade Federal de Sergipe, São Cristóvão-SE, 2018.

JUCÁ, Leina Claudia Viana. Das histórias que nos habitam: por uma formação de professores de inglês para o Brasil. 2017. 268f. Tese (Doutorado em estudos Linguísticos), Universidade de São Paulo, São Paulo, 2017.

LIMA, Roberto de Souza. Os PCN-LE e a prática docente: realidade ou utopia. Dissertação. (Mestrado em Linguística Aplicada). Universidade de Brasília, Brasília, 2005.

MACIEL, Ruberval Franco. Negociando e construindo conhecimentos e práticas locais: a formação de professores de língua inglesa e os documentos oficiais. 2013. 183f. Tese (Doutorado em estudos Linguísticos), Universidade de, São Paulo, São Paulo, 2013. 
MENEGAZZO, Maria Alice. Os PCNEM e $\mathrm{PCN}_{+}$de língua estrangeira: sugestões aplicáveis, Dissertação (Mestrado em Estudos da Linguagem), Universidade Estadual de Londrina, Londrina-PR, 2006.

MIRANDA, Nilva Conceição. Ensino de língua inglesa no Brasil, políticas educacionais e a formação do sujeito da educação básica. 2015. 112f. Dissertação (Mestrado em Educação), Universidade Federal do Paraná, Curitiba, 2015.

NASCIMENTO, Laudo Natel do. A formação do professor de língua inglesa e a legislação: o caso do curso de letras - habilitação português-inglês da UFS. Dissertação (Mestrado em Educação) - Universidade Federal de Sergipe, São Cristovão, SE, 2010.

OLIVEIRA, Cleiton de. A pesquisa sobre municipalização do ensino: algumas tendências. In: OLIVEIRA, Dalila Andrade; ROSAR, Maria de Fátima. Politica e gestão da educação. 3. ed. Belo Horizonte: Autêntica, 2010, p. 78-91.

OLIVEIRA, Ênio de. Políticas de Ensino de Línguas Estrangeiras em Escolas Públicas do Estado de São Paulo. Dissertação (Mestrado em Estudos da Linguagem) Universidade Estadual de Campinas, Campinas, SP, 2003.

OLIVEIRA, Luiz Eduardo. A instituição das línguas vivas no Brasil: o caso da Língua Inglesa (1809-1890). Tese (Doutorado) - Pontifícia Universidade Católica de São Paulo. Programa de Estudos Pós-Graduados em Educação: Histórica, Política e Sociedade. São Paulo, 2006.

OLIVEIRA, Pauliana Duarte. O imaginário do aluno sobre a língua inglesa na constituição de sua subjetividade. Dissertação (Mestrado em Linguística) Universidade Federal de Uberlândia, Uberlândia, MG, 2006.

PUCCI, Renata Helena Pin. O ensino da língua inglesa na escola pública: um olhar para os sentidos construídos por seus professores acerca de onde, para quem, porque e como ensinam. 2017. 145f. Tese (Doutorado em Educação), Universidade Metodista de Piracicaba, Piracicaba, 2017.

ROCHA, Claudia Hilsdorf. Provisões para ensinar LE no ensino fundamental de $\mathbf{1}^{\mathrm{a}}$ a $4^{\text {a }}$ séries: dos Parâmetros oficiais e objetivos dos agentes. Dissertação (Mestrado em Linguística Aplicada), Universidade Estadual de Campina, Campinas-SP, 2006.

ROCHA, Luana Franco. O ensino de língua estrangeira em Niterói: Um Olhar Político-Linguístico. Dissertação (Mestrado em Estudos da Linguagem) - Universidade Federal Fluminense, Rio de Janeiro, RJ, 2016.

SANTOS, Isadora Maria Falbot dos. O ensino de língua inglesa em duas escolas pública de Cuiabá: com a palavra, as professoras. Dissertação (Mestrado em Estudos da Linguagem), Universidade Federal de Mato Grosso, Cuiabá-MT, 2014.

SANTOS, Andressa Cristiane. Proposta curricular do Estado de São Paulo: a relação entre as crenças e a prática de dois professores de inglês. 2015. 164f. Dissertação (Mestrado em Estudos Linguísticos), Universidade Estadual Paulista, São José do Rio Preto, 2015. 
SANTOS, Elaine Maria. Entre a tradição e a inovação: professores e compêndios de inglês do século XIX. 2017. 325f. Tese (Doutorado em Educação), Universidade Federal do Sergipe, São Cristóvão, 2017.

SECATTO, Mariana Guedes. Políticas Linguísticas e as representações da prática docente no ensino fundamental I: língua inglesa. Dissertação (Mestrado em Estudos da Linguagem). IEL/UNICAMP, Campinas, 2016.

SOUZA, Sérgio Augusto Freire de. O movimento dos sentidos sobre línguas estrangeiras no Brasil: discurso, história e educação. Tese (Doutorado em Linguística). IEL/Unicamp, Campinas, SP, 2005.

SOUSA, Renata Maria Rodrigues Quirino. Professores de Inglês da Escola Pública: investigações sobre suas identidades numa rede de conflitos. Dissertação (Mestrado em Letras), Universidade de São Paulo, São Paulo, 2006.

TOMASEL, Soraia. “To be or not to be”: A produção da docência de Língua Inglesa em documentos legais, Dissertação (Mestrado em educação), Universidade do Vale do Rio dos Sinos, São Leopoldo-RS, 2017.

VIDOTTI, Joselita Júnia Viegas. Políticas linguísticas para o ensino de língua estrangeira no brasil do século XIX, com ênfase na língua inglesa. 2012. 245f. Tese (Doutorado em Estudos Linguísticos e Literários), Universidade de São Paulo, São Paulo, 2012.

VINCENTIN, Karina Aparecida. Inglês nos anos iniciais do Ensino Fundamental Público: de representaçoes de professores a políticas linguisticas. 2013. 149f.

Dissertação (Mestrado em Linguistica Aplicada), Universidade Estadual de Campinas, Campinas, 2013.

\section{Como referenciar este artigo}

SCAGLION. Luiz Fernando; ARAÚJO, Luciana Aparecida; GIROTO, Claudia Regina Mosca. A inserção da Língua Inglesa no currículo das séries iniciais das escolas brasileiras. Rev. EntreLínguas, Araraquara, v. 5, n. 2, p. 359-377, jul./dez. 2019. E-ISSN: 2447-3529. DOI: 10.29051/el.v5i2.12890

Submetido em: 01/04/2019

Revisões requeridas: 10/05/2019

Aprovado em: 30/06/2019

Publicado em: 01/10/2019 